\title{
Initiation of a Marinoan Snowball Earth in a state-of-the-art atmosphere-ocean general circulation model
}

\author{
A. Voigt ${ }^{1,2}$, D. S. Abbot ${ }^{3}$, R. T. Pierrehumbert ${ }^{3}$, and J. Marotzke ${ }^{1}$ \\ ${ }^{1}$ Max Planck Institute for Meteorology, Hamburg, Germany \\ ${ }^{2}$ International Max Planck Research School on Earth System Modelling, Hamburg, Germany \\ ${ }^{3}$ Department of Geophysical Sciences, University of Chicago, Chicago, Illinois, USA
}

Received: 9 September 2010 - Published in Clim. Past Discuss.: 23 September 2010

Revised: 4 January 2011 - Accepted: 8 February 2011 - Published: 10 March 2011

\begin{abstract}
We study the initiation of a Marinoan Snowball Earth $(\sim 635$ million years before present $)$ with the state-of-the-art atmosphere-ocean general circulation model ECHAM5/MPI-OM. This is the most sophisticated model ever applied to Snowball initiation. A comparison with a preindustrial control climate shows that the change of surface boundary conditions from present-day to Marinoan, including a shift of continents to low latitudes, induces a globalmean cooling of $4.6 \mathrm{~K}$. Two thirds of this cooling can be attributed to increased planetary albedo, the remaining one third to a weaker greenhouse effect. The Marinoan Snowball Earth bifurcation point for pre-industrial atmospheric carbon dioxide is between 95.5 and $96 \%$ of the present-day total solar irradiance (TSI), whereas a previous study with the same model found that it was between 91 and $94 \%$ for presentday surface boundary conditions. A Snowball Earth for TSI set to its Marinoan value (94\% of the present-day TSI) is prevented by doubling carbon dioxide with respect to its preindustrial level. A zero-dimensional energy balance model is used to predict the Snowball Earth bifurcation point from only the equilibrium global-mean ocean potential temperature for present-day TSI. We do not find stable states with sea-ice cover above 55\%, and land conditions are such that glaciers could not grow with sea-ice cover of 55\%. Therefore, none of our simulations qualifies as a "slushball" solution. While uncertainties in important processes and parameters such as clouds and sea-ice albedo suggest that the Snowball Earth bifurcation point differs between climate models, our results contradict previous findings that Snowball Earth initiation would require much stronger forcings.
\end{abstract}

Correspondence to: A. Voigt

(aiko.voigt@zmaw.de)

\section{Introduction}

The apparent existence of low-latitude land glaciers at sea level during at least two episodes of the Neoproterozoic era, the Sturtian $(\sim 710$ million years before present, Ma) and the Marinoan ( $\sim 635 \mathrm{Ma})$ (Evans, 2000; Trindade and Macouin, 2007; Macdonald et al., 2010), has led to the proposal that these glaciations were accompanied by completely ice-covered oceans. These states have become popular under the term "(hard) Snowball Earth" and are at the heart of the Snowball Earth hypothesis (Kirschvink, 1992; Hoffman et al., 1998), which also yields explanations for banded iron formations and cap carbonates (Hoffman and Schrag, 2002). Snowball Earth episodes have not only attracted the attention of geologists, but also of climate modelers, who have attempted to test whether the Snowball Earth hypothesis is compatible with climate physics.

The Snowball Earth hypothesis relies on a runaway icealbedo feedback that can be seen in simple energy balance models (e.g., Budyko, 1969; Sellers, 1969). After the initial perception that the Snowball Earth hypothesis is, in principle, compatible with climate physics, the last decade has seen the full hierarchy of climate models being applied to Snowball Earth initiation. While this has lead to invaluable insight into the processes important for Snowball Earth initiation and while we do not know of any climate model that excludes Snowball Earth solutions categorically, various climate modelling studies have found that initiating completely ice-covered oceans requires forcings (Chandler and Sohl, 2000; Poulsen et al., 2002; Poulsen, 2003; Poulsen and Jacob, 2004) that might be considered unrealistic for the Neoproterozoic. In particular, it has been argued that Snowball Earth initiation is much more difficult in models that include a dynamical ocean than in models that do not (Poulsen et al., 2002; Poulsen, 2003).

Published by Copernicus Publications on behalf of the European Geosciences Union. 
At the same time, Hyde et al. (2000) and Peltier et al. (2004), using an energy balance model with interactive ice sheets, found so-called "Slushball Earth" or "oasis" solutions in which tropical land glaciers can coexist with large areas of perennially open tropical water. Although their model neglected important physical processes such as atmosphere and ocean dynamics, these solutions were supported by an atmosphere general circulation model coupled to a slab ocean and prescribed full continental glaciation (Hyde et al., 2000; Baum and Crowley, 2001). Moreover, Chandler and Sohl (2000) and Micheels and Montenari (2008) found, also using atmosphere general circulation models coupled to slab oceans, solutions with equatorial land masses below freezing in conjunction with almost but not completely ice-covered oceans. Despite the fact that climate model results should be interpreted with care because of uncertainties in important parameters and processes (e.g. Poulsen and Jacob, 2004), the reported difficulties in initiating a Snowball Earth in some climate models have lead to the impression among some that, from the perspective of climate modelling, the Snowball Earth hypothesis is less plausible than the Slushball Earth hypothesis (Lubick, 2002; Kerr, 2010).

In this paper, we use the state-of-the-art atmosphereocean general circulation model ECHAM5/MPI-OM to study Snowball Earth initiation for Marinoan surface boundary conditions, for which most of the continents are at low latitudes. We investigate the total solar irradiance (TSI) and atmospheric $\mathrm{CO}_{2}$ level that cause a Snowball Earth bifurcation as well as the maximum stable sea-ice cover. By comparing these simulations to previous simulations with the same model for present-day surface boundary conditions (Voigt and Marotzke, 2010), we find that low-latitude continents favor Snowball Earth initiation, as suggested by Kirschvink (1992). Our climate model is the first model that at the same time takes into account ocean dynamics, sea-ice dynamics and interactive clouds. All three processes were found to be essential for Snowball Earth initiation (Poulsen et al., 2001; Poulsen and Jacob, 2004; Lewis et al., 2003, 2007). Our model includes neither sea-ice glaciers nor interactive land glaciers, both of which should facilitate Snowball Earth initiation. We therefore expect that the ECHAM5/MPI-OM model would enter Snowball Earth states at even higher values of solar insolation and $\mathrm{CO}_{2}$ than we find here if it included these effects.

The paper is organized as follows. Section 2 describes the climate model, the Marinoan surface boundary conditions, and the setup of the ECHAM5/MPI-OM simulations. Section 3 analyzes the Marinoan control climate and compares it to a pre-industrial control simulation by means of a one-dimensional energy balance model of zonal-mean surface temperature. This enables us to investigate the climatic effect of changing surface boundary conditions from presentday to Marinoan. Section 4 investigates the Snowball Earth bifurcation point and maximum stable sea-ice cover. A zerodimensional energy balance model of global-mean ocean potential temperature is used to predict the Snowball Earth bifurcation point in Sect. 5. Section 6 gives a general discussion of the results, Sect. 7 follows with conclusions. The appendix points at an imbalance of the diagnosed global-mean top of atmosphere and surface energy fluxes found in some of our simulations.

\section{Model and simulation setup}

We apply the state-of-the-art atmosphere-ocean general circulation model ECHAM5/MPI-OM. This is the same model that was used to study the transition to a Snowball Earth for present-day boundary conditions (Voigt and Marotzke, 2010), apart from technical changes to adapt the model to the new supercomputer of the German Climate Computing Center (DKRZ). ECHAM5/MPI-OM ranks among the world's top climate models (Reichler and Kim, 2008) and has been used for a variety of applications, ranging from climate projections for the Intergovernmental Panel on Climate Change (Solomon et al., 2007) to paleo-climate simulations of the Holocene and Eemian (Fischer and Jungclaus, 2010) as well as the Paleocene/Eocene (Heinemann et al., 2009).

Comprehensive documentation of the atmosphere model ECHAM5 (we use version ECHAM5.3.02p) is given by Roeckner et al. (2003). Details of the ocean model MPIOM (here used in version 1.2.3p2) are described by Marsland et al. (2003). We here only review the model features and boundary conditions that are salient to our study and its comparison to previous Snowball Earth initiation studies.

Our Marinoan continents follow the reconstruction of M. Macouin (personal communication, 2009) and are similar to, though less dispersed than, the continents used by Le Hir et al. (2009) (Fig. 1). In contrast to today, landmasses are largely clustered from $45^{\circ} \mathrm{S}$ to $30^{\circ} \mathrm{N}$ with two large equatorial continents separated by a narrow seaway. Zonal-mean land fraction from $60^{\circ} \mathrm{S}$ to $20^{\circ} \mathrm{N}$ is higher in the Marinoan than today, with the majority of the Marinoan landmasses located in the Southern Hemisphere (Fig. 2). We set land surface albedo to 0.272 everywhere (see Table 1 ). This value is chosen such that the global-mean background surface albedo (i.e., the surface albedo for zero sea-ice and snow cover) of the Marinoan setup equals that of the present-day setup. This land albedo is close to the surface albedo of deserts suggested by Hagemann (2002) and is consistent with the fact that land vegetation had not yet developed in the Marinoan. Forest ratio, vegetation ratio, and leaf area index consequently are zero. No land glaciers are prescribed. Surface roughness length and soil-water holding capacity are specified to bare desert values of $5 \times 10^{-3} \mathrm{~m}$ and $0.1 \mathrm{~m}$, respectively (Hagemann, 2002).

The presence of snow increases land surface albedo according to the fractional snow cover of the grid cell. Land snow albedo depends on surface temperature and ranges from 0.3 at $0{ }^{\circ} \mathrm{C}$ to 0.8 at or below $-5^{\circ} \mathrm{C}$. Ocean surface 


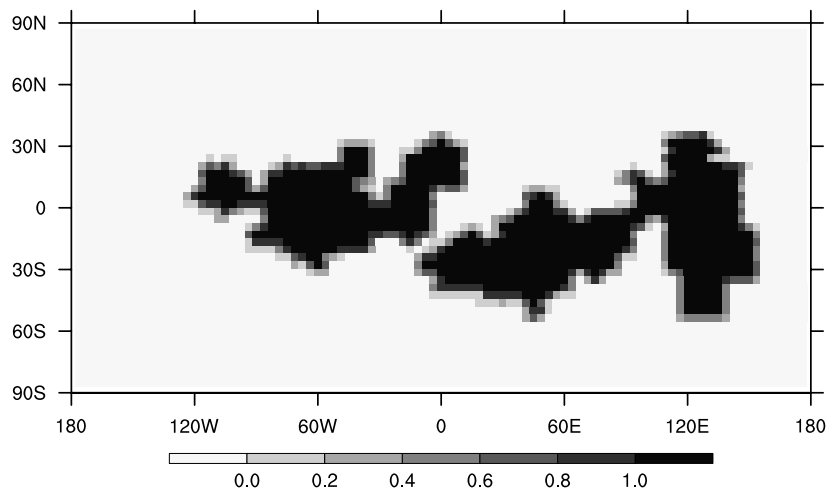

Fig. 1. Marinoan land-sea mask. Values of 1 correspond to pure land points, values of 0 to pure ocean points. Mixed grid boxes with land and ocean cover occur at the continental edges.

albedo is set to 0.07. Bare sea-ice albedo depends on sea-ice temperature and ranges from 0.55 at $0{ }^{\circ} \mathrm{C}$ to 0.75 at or below $-1{ }^{\circ} \mathrm{C}$. Snow on sea ice leads to the following albedo increase: if the water equivalent of snow depth is larger than $0.01 \mathrm{~m}$, sea ice is treated as snow-covered. The albedo of snow-covered sea ice depends on snow surface temperature and ranges from 0.65 at $0{ }^{\circ} \mathrm{C}$ to 0.8 at or below $-1{ }^{\circ} \mathrm{C}$. The sea-ice model follows the dynamics of Hibler (1979) while the thermodynamics are incorporated by a zero-layer Semtner model that relates changes in sea-ice thickness to a balance of radiative, turbulent, and oceanic heat fluxes (Semtner, 1976). The freezing point of sea water is fixed to $-1.9{ }^{\circ} \mathrm{C}$ independent of salinity. Snow on ice is explicitly modeled, including snow/ice transformation when the snow/ice interface sinks below the sea level because of snow loading. The effect of ice formation and melting is accounted for by assuming a sea-ice salinity of 5 psu. The sea-ice thickness is limited to about $8 \mathrm{~m}$.

Orbital parameters are constant in time and correspond to year $800 \mathrm{AD}$. Ozone follows the 1980-1991 climatology of Fortuin and Kelder (1998), aerosols are prescribed according to Tanré et al. (1984). Greenhouse gases are set to pre-industrial levels $\left(\mathrm{CO}_{2}=278 \mathrm{ppm}, \mathrm{CH}_{4}=650 \mathrm{ppb}\right.$, $\mathrm{N}_{2} \mathrm{O}=270 \mathrm{ppb}$, no CFC's). Lacking information on Marinoan orography we set land surface elevation to $100 \mathrm{~m}$ everywhere, implying that ECHAM5's parameterization of gravity wave drag due to subgrid-scale orography (Lott and Miller, 1997) is inactive in the Marinoan setup whereas it was active for the pre-industrial control simulation PI (see below) and the initiation of a modern Snowball Earth (Voigt and Marotzke, 2010). Lateral water flow on continents is directed towards the nearest grid box with non-zero ocean fraction; no rivers or lakes are prescribed.

For the atmosphere model, ECHAM5, horizontal resolution is set to spectral truncation $\mathrm{T} 31\left(\sim 3.75^{\circ}\right)$. In the vertical, 19 hybrid $\sigma$-levels that extend up to $10 \mathrm{hPa}$ are employed. The time step for the atmosphere model is $2400 \mathrm{~s}$. The ocean
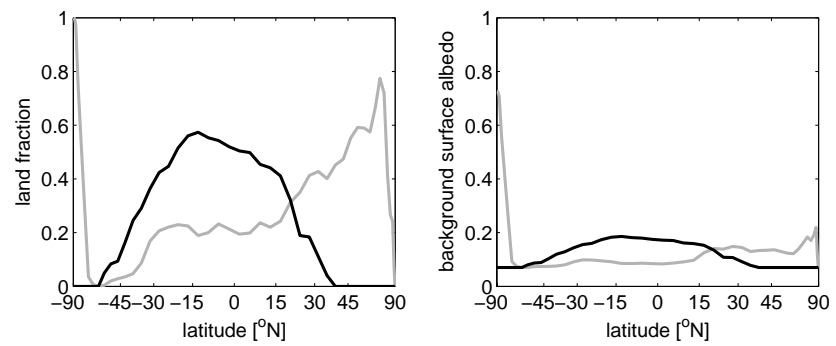

Fig. 2. Zonal-mean land-sea mask (left) and background surface albedo (right) of the Marinoan (black) and present-day (gray) setup. The abscissa is linear in sine of latitude such that the spacing between the latitudes is proportional to the Earth's surface area between them.

Table 1. ECHAM5 input parameters for the Marinoan control simulation MAR and the pre-industrial control simulation PI. MAR uses a fixed orbit whose parameters are chosen to match the temporally varying orbital parameters of PI at year $800 \mathrm{AD}$. PI uses the VSOP87 orbit (Variations Séculaire des Orbites Planétaires) of Bretagnon and Francou (1988), values given here are for year $800 \mathrm{AD}$ according to Berger (1978) and are taken from http://aom.giss.nasa. gov/srorbpar.html. Land surface albedo, soil data and land surface roughness length are globally uniform in MAR but vary spatially in PI; for the latter mean values are given. MAR's FAO soil data flag corresponds to sand. The pre-industrial control simulation is the same as in Voigt and Marotzke (2010).

\begin{tabular}{|c|c|c|}
\hline input parameter & MAR & PI \\
\hline $\mathrm{CO}_{2}$ & $278 \mathrm{ppm}$ & $286.2 \mathrm{ppm}$ \\
\hline $\mathrm{CH}_{4}$ & $650 \mathrm{ppb}$ & $805.6 \mathrm{ppb}$ \\
\hline $\mathrm{NO}_{2}$ & $270 \mathrm{ppb}$ & $276.7 \mathrm{ppb}$ \\
\hline ozone & present-day & present-day \\
\hline aerosols & Tanré & Tanré \\
\hline CFC's & none & none \\
\hline total solar irradiance & $1367 \mathrm{~W} \mathrm{~m}^{-2}$ & $1367 \mathrm{~W} \mathrm{~m}^{-2}$ \\
\hline orbit & $\begin{array}{l}\text { present-day and } \\
\text { fixed in time }\end{array}$ & $\begin{array}{l}\text { present-day and } \\
\text { changing in time }\end{array}$ \\
\hline eccentricity & 0.0172 & 0.0172 \\
\hline obliquity & $23.59^{\circ}$ & $23.59^{\circ}$ \\
\hline longitude of perihelion & $262.41^{\circ}$ & $262.41^{\circ}$ \\
\hline land fraction & 0.259 & 0.284 \\
\hline land surface albedo & 0.272 & 0.254 \\
\hline ocean surface albedo & 0.07 & 0.07 \\
\hline vegetation & none & present-day \\
\hline maximum field capacity of soil & $0.1 \mathrm{~m}$ & $0.6 \mathrm{~m}$ \\
\hline FAO soil data flag & 1 & 2.6 \\
\hline glaciers & none & present-day \\
\hline surface roughness length over land & $0.005 \mathrm{~m}$ & $1.6 \mathrm{~m}$ \\
\hline land surface elevation & $100 \mathrm{~m}$ & $901 \mathrm{~m}$ \\
\hline $\begin{array}{l}\text { gravity wave drag due to } \\
\text { subgrid-scale orography }\end{array}$ & off & on \\
\hline
\end{tabular}


Table 2. Summary of ECHAM5/MPI-OM simulations. The applied total solar irradiance is given in percentage of the present-day value $1367 \mathrm{~W} \mathrm{~m}^{-2}$, atmospheric carbon dioxide in percentage of the pre-industrial level used in MAR. SE abbreviates Snowball Earth. Unless otherwise stated, simulations are started from year 3499 of MAR.

\begin{tabular}{|c|c|c|c|c|c|}
\hline simulation & TSI & $\mathrm{CO}_{2}$ & $\begin{array}{l}\text { simulated } \\
\text { years }\end{array}$ & result & remark \\
\hline PI & $100 \%$ & $286.2 \mathrm{ppm}$ & 100 & pre-industrial control run & \\
\hline MAR & $100 \%$ & $100 \%$ & $3400-3499$ & Marinoan control run & \\
\hline TSIO0 & $0.01 \%$ & $100 \%$ & $3500-3509$ & SE at year 3509 & \\
\hline TSI94 & $94 \%$ & $100 \%$ & $3500-3999$ & SE at year 3854 & \\
\hline TSI96 & $96 \%$ & $100 \%$ & $3500-6199$ & $\begin{array}{l}\text { sea-ice line at } 30^{\circ} \mathrm{N} / 25^{\circ} \mathrm{S} \\
\text { at year } 6199\end{array}$ & $\begin{array}{l}\text { ocean time step of } \\
3600 \mathrm{~s} \text { after year } 3979\end{array}$ \\
\hline TSI98 & $98 \%$ & $100 \%$ & $3500-3999$ & $\begin{array}{l}\text { sea-ice line at } 40^{\circ} \mathrm{N} / \mathrm{S} \\
\text { at year } 3999\end{array}$ & \\
\hline TSI94-2CO2 & $94 \%$ & $200 \%$ & $3500-5299$ & $\begin{array}{l}\text { sea-ice line at } 30^{\circ} \mathrm{N} / 25^{\circ} \mathrm{S} \\
\text { at year } 5299\end{array}$ & $\begin{array}{l}\text { ocean time step of } \\
3600 \text { s after year } 3902\end{array}$ \\
\hline TSI94-4CO2 & $94 \%$ & $400 \%$ & $3500-4999$ & $\begin{array}{l}\text { sea-ice line at } 40^{\circ} \mathrm{N} / \mathrm{S} \\
\text { at year } 4999\end{array}$ & \\
\hline TSI94-6CO2 & $94 \%$ & $600 \%$ & $3500-4999$ & $\begin{array}{l}\text { sea-ice line at } 47^{\circ} \mathrm{N} / \mathrm{S} \\
\text { at year } 4999\end{array}$ & \\
\hline TSI955 & $95.5 \%$ & $100 \%$ & $5800-6019$ & SE at year 6000 & started from year \\
\hline TSI100 & $100 \%$ & $100 \%$ & $4000-4099$ & stable SE & $\begin{array}{l}5799 \text { of TSI96, ocean } \\
\text { time step of } 3600 \mathrm{~s} \\
\text { started from } \\
\text { year } 3999 \text { of TSI94 }\end{array}$ \\
\hline
\end{tabular}

model MPI-OM applies a curvilinear grid with $114 \times 106$ points and poles over the two continents $\left(51^{\circ} \mathrm{W} / 23^{\circ} \mathrm{N}\right.$ and $\left.128^{\circ} \mathrm{E} / 46^{\circ} \mathrm{S}\right)$, resulting in high horizontal resolution with grid distances smaller than $50 \mathrm{~km}$ near the grid's poles but low resolution with grid distances up to $435 \mathrm{~km}$ in parts of the Northern Hemisphere (see Voigt, 2010 for details). We use 39 vertical levels, with the top level having a thickness of $22 \mathrm{~m}$. The time step for the ocean model is $5760 \mathrm{~s}$. Some simulations require a reduced time step of $3600 \mathrm{~s}$ to overcome numerical instabilities (see Table 2). Marinoan ocean bathymetry is set to $5000 \mathrm{~m}$ everywhere. The atmosphere and ocean models are coupled via the OASIS3 coupler (Valcke et al., 2003) with a coupling time step of one day. No flux adjustments are applied.

We initialize ECHAM5/MPI-OM from warm atmospheric conditions and a homogeneous ocean at rest and at potential temperature of $283 \mathrm{~K}$ and a salinity of $34.3 \mathrm{psu}$. The latter is approximately the salinity we would obtain in the present-day ocean if all glaciers were melted completely (Heinemann et al., 2009). The model is then run to equilibrium at today's total solar irradiance and pre-industrial greenhouse gas levels by integrating it for 3500 years. Years 3400 to 3499 of this spin-up serve as Marinoan control simulation (MAR).

Simulations with reduced total solar irradiance (TSI), in some cases combined with an increase of atmospheric carbon dioxide, are started from year 3499 of MAR (see Table 2). An additional simulation with total solar irradiance reduced to $95.5 \%$ (TSI955) is started from year 5799 of TSI96. Moreover, we perform one simulation where we set TSI back to $100 \%$ after complete sea-ice cover has been accomplished (TSI100). Throughout this study, years are counted with respect to model initialization at year 0 .

In the following section, we compare the Marinoan control climate MAR to the pre-industrial control climate PI used in Voigt and Marotzke (2010) and obtained from the CERA database (Roeckner, 2007). PI applies slightly higher levels of atmospheric carbon dioxide, methane and nitrous oxide than MAR (see Table 1). Based on Myhre et al. (1998) we estimate that this causes a radiative forcing of $-0.27 \mathrm{Wm}^{-2}$ between PI and MAR, i.e., less than $0.1 \%$ of the global-mean incident shortwave radiation at the top of the atmosphere. In what follows, we neglect this small effect and discuss PI and MAR as if they employed the same levels of carbon dioxide, methane and nitrous oxide. Moreover, after the simulations have been completed we noticed that the Marinoan runs use Pacanowski-Philander vertical viscosity and diffusivity parameters (Marsland et al., 2003) that are divided by five compared to the values used for the pre-industrial control run PI and the transition to a modern Snowball Earth (Voigt and Marotzke, 2010). Test runs have shown that the results of this paper are robust with respect to this unintended parameter change (Voigt, 2010). 

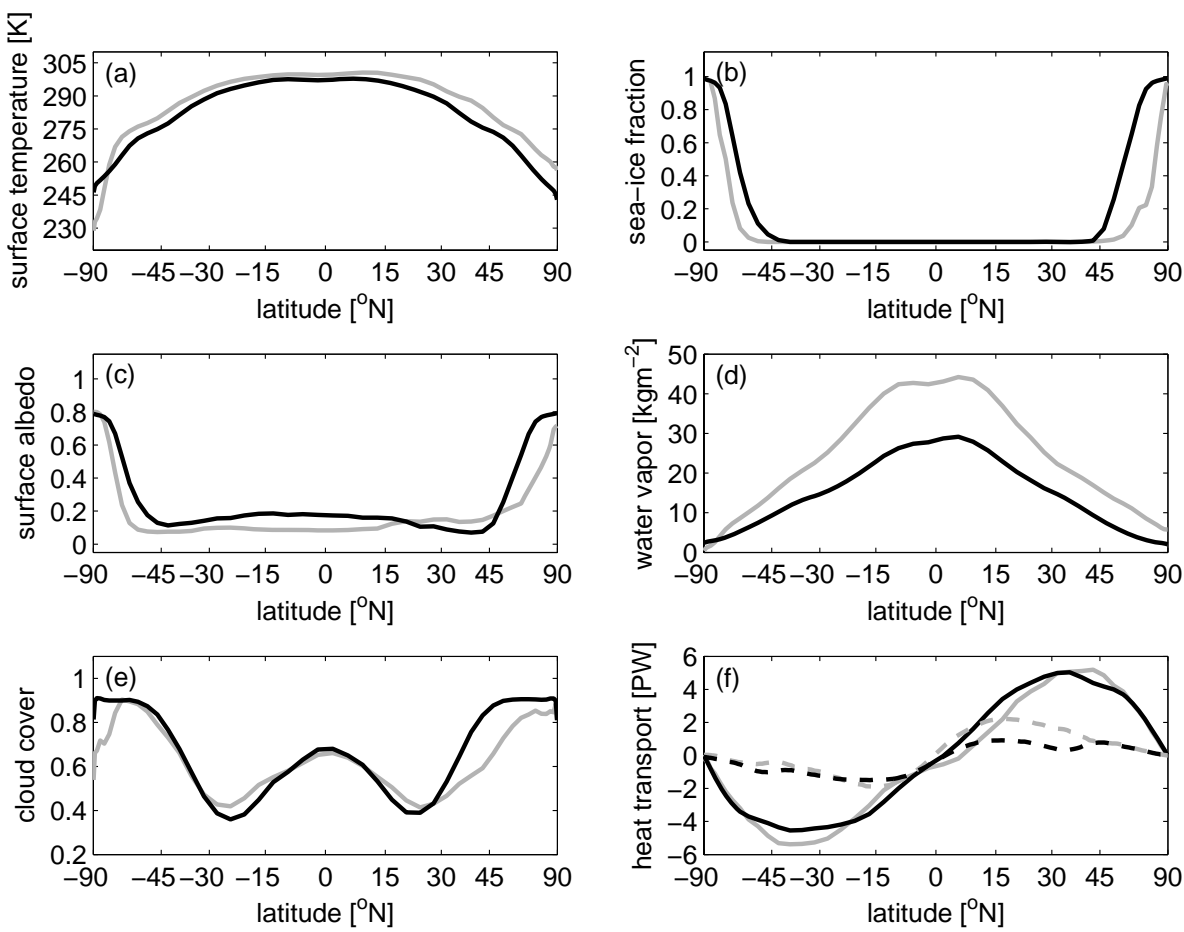

Fig. 3. Time and zonally averaged surface temperature (a), (b) sea-ice fraction (only taking into account ocean points), (c) surface albedo, (d) vertically integrated water vapor, (e) cloud cover, and (f) atmosphere (solid) and ocean (dashed) heat transport in MAR (black) and PI (gray). The abscissae are linear in sine of latitude.

\section{Marinoan control climate and comparison to the pre-industrial control climate}

In this section, we describe the annual-mean Marinoan control climate MAR and compare it to the annual-mean preindustrial control climate PI. Using a one-dimensional energy balance model we quantify how much of the cooling from PI to MAR is caused by differences in planetary albedo, effective emissivity (i.e., the greenhouse effect), and meridional heat transports.

\subsection{Surface climate}

The Marinoan setup results in a global annual-mean surface temperature of $283 \mathrm{~K}$. This is $4.6 \mathrm{~K}$ colder than the preindustrial control climate PI (Table 3). Zonal-mean surface temperature is largely symmetric about the equator (Fig. 3), with tropical temperatures of $298 \mathrm{~K}$ and polar temperatures of $245 \mathrm{~K}$. This implies an equator-to-pole temperature contrast of $53 \mathrm{~K}$, slightly higher than the Northern Hemisphere contrast in PI. Close to the South Pole, replacing the hightopography Antarctic ice sheet of PI by sea-ice covered ocean in MAR causes a local surface warming of more than $10 \mathrm{~K}$ in MAR compared to PI. Land surface temperatures tend to be higher than sea-surface temperatures, with annual-mean surface temperatures of up to $302 \mathrm{~K}$ in the continents' interior. Sea ice extends to $45^{\circ} \mathrm{N} / \mathrm{S}$ in the annual mean. Poleward
Table 3. Global annual-mean values of key climate variables for the Marinoan (MAR) and pre-industrial (PI) control simulations. Planetary albedo and effective emissivity are calculated using global annual-mean radiative fluxes.

\begin{tabular}{lll}
\hline & MAR & PI \\
\hline surface temperature & $283.0 \mathrm{~K}$ & $287.6 \mathrm{~K}$ \\
mean ocean potential temperature & $274.3 \mathrm{~K}$ & $277.5 \mathrm{~K}$ \\
sea-ice area & $8.6 \times 10^{13} \mathrm{~m}^{2}$ & $2.1 \times 10^{13} \mathrm{~m}^{2}$ \\
planetary albedo & 0.351 & 0.321 \\
surface albedo & 0.244 & 0.170 \\
effective emissivity & 0.594 & 0.583 \\
vertically integrated water vapor & $15.5 \mathrm{~kg} \mathrm{~m}^{-2}$ & $25.1 \mathrm{~kg} \mathrm{~m}^{-2}$ \\
total cloud cover & 0.654 & 0.620 \\
shortwave cloud radiative forcing & $-48.8 \mathrm{~W} \mathrm{~m}^{-2}$ & $-53.9 \mathrm{~W} \mathrm{~m}^{-2}$ \\
longwave cloud radiative forcing & $30.0 \mathrm{~W} \mathrm{~m}^{-2}$ & $28.7 \mathrm{~W} \mathrm{~m}^{-2}$ \\
\hline
\end{tabular}

of $70^{\circ} \mathrm{N} / \mathrm{S}$, the ocean is covered with sea-ice year-round. Annual-mean sea-ice thickness is less than $3 \mathrm{~m}$ equatorward of $70^{\circ} \mathrm{N} / \mathrm{S}$, but as high as $7 \mathrm{~m}$ near the poles. Except very close to the annual-mean sea-ice margin, sea ice is everywhere covered by snow thicker than $0.01 \mathrm{~m}$ water equivalent. Most parts of the continents are snow-free; land snowcover is restricted to the southernmost parts of the continents where snow depth reaches a water equivalent of $0.07 \mathrm{~m}$ at 

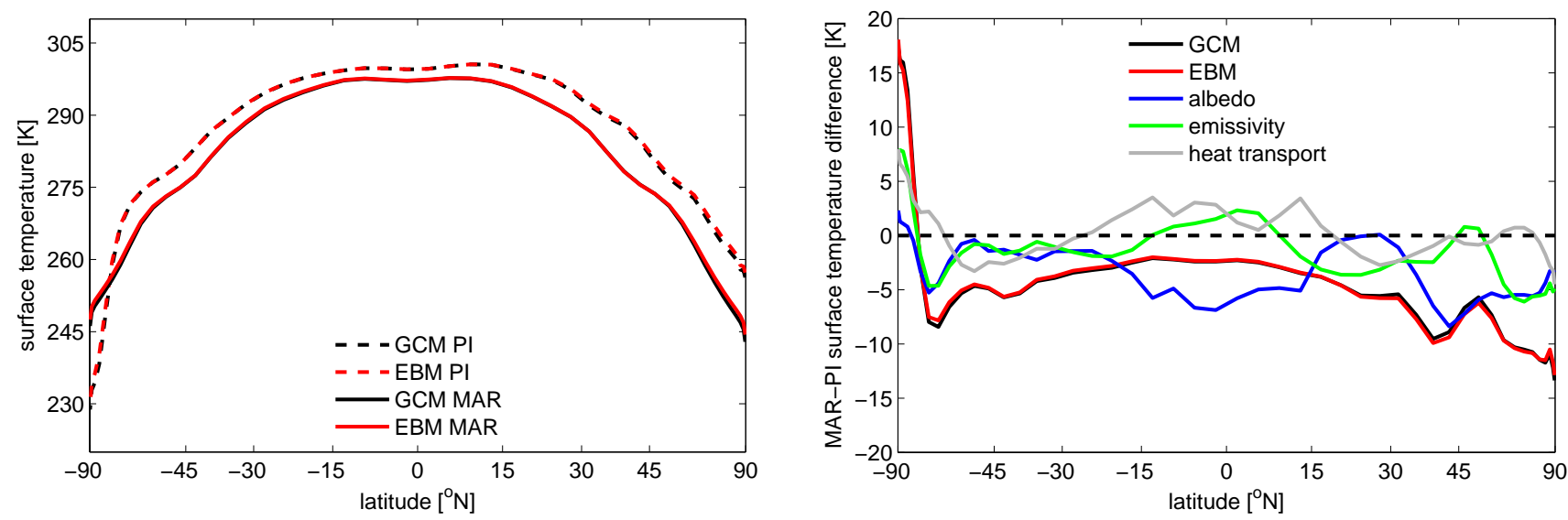

Fig. 4. Left: time and zonally averaged surface temperature of MAR (solid) and PI (dashed) as simulated by the atmosphere-ocean general circulation model (GCM, black) and diagnosed by the one-dimensional energy balance model (EBM, red). Right: difference of time and zonally averaged surface temperature between MAR and PI as simulated by the general circulation model (black) and diagnosed by the onedimensional energy balance model (red). The other solid lines show the MAR-PI surface temperature differences attributed to differences in planetary albedo (blue), effective emissivity (green), and heat transport (gray). The abscissae are linear in sine of latitude.

$133^{\circ} \mathrm{E} / 50^{\circ} \mathrm{S}$ and of $0.02 \mathrm{~m}$ at $45^{\circ} \mathrm{E} / 52^{\circ} \mathrm{S}$. As expected in a cooler climate, the vertically integrated water vapor content is lower in MAR than in PI at all latitudes except close to the South Pole. Cloud cover in MAR is higher compared to PI in the tropics and poleward of $30^{\circ} \mathrm{N} / \mathrm{S}$ but lower in the subtropics.

Atmospheric heat transport is larger in MAR than in PI in the tropics, as a result of more vigorous Hadley cells, but smaller in SH midlatitudes due to reduced eddy transport. Poleward ocean heat transport is reduced in MAR compared to PI except in SH midlatitudes. This change is reflected in the contribution of the meridional overturning circulation which, for example, shows southward heat transport around $30^{\circ} \mathrm{N}$ as a consequence of a strong anticlockwise (viewed from the East) Ekman cell that nearly reaches the ocean bottom (not shown). While a detailed analysis of MAR's ocean circulation is not the aim of this study, we note that deep Ekman cells in the absence of zonal boundaries have also been reported in aquaplanet simulations with coupled atmosphereocean general circulation models (Smith et al., 2006; Marshall et al., 2007).

\subsection{One-dimensional energy balance model}

To gain quantitative insight into how differences in radiation and heat transport contribute to the differences between the Marinoan and pre-industrial control climates, we apply the one-dimensional energy balance model (1d-EBM) of zonalmean surface temperature developed by Heinemann et al. (2009).

Assuming equilibrium and taking the zonal mean, net incoming shortwave radiation at the top of atmosphere (TOA) must be balanced by outgoing longwave radiation (OLR) and divergence of meridional heat transport at each latitude (e.g.,
Stone, 1978). If we further parameterize OLR in terms of surface temperature, $\tau$, and effective emissivity, $\epsilon$, we have

$(1-\alpha(\phi)) Q(\phi)=\sigma \epsilon(\phi) \tau^{4}(\phi)+H(\phi)$,

where $\alpha$ denotes planetary albedo, $\phi$ latitude, $Q$ TOA incoming shortwave radiation, $\sigma=5.67 \times 10^{-8} \mathrm{~W} \mathrm{~m}^{-2} \mathrm{~K}^{-4}$ the Stefan-Boltzmann constant, and $H$ divergence of meridional heat transport. All quantities are averaged over time and longitude. Solving Eq. (1) for $\tau$ yields the 1d-EBM estimate of surface temperature, $\tau_{\mathrm{ebm}}$,

$$
\begin{aligned}
\tau_{\mathrm{ebm}}(\phi) & \equiv \tau(\phi) \\
& =\sqrt[4]{\frac{1}{\sigma \epsilon(\phi)}\{(1-\alpha(\phi)) Q(\phi)-H(\phi)\}},
\end{aligned}
$$

with $\alpha, Q, \epsilon$, and $H$ diagnosed from the TOA and surface radiative fluxes of the GCM as described in Heinemann et al. (2009). The 1d-EBM's surface temperature only marginally deviates from the GCM simulated surface temperature (see Fig. 4), with the error in the 1d-EBM's surface temperature estimate caused by time and zonal variations of surface temperature (Voigt, 2010).

The one-dimensional energy balance does not help to understand why a particular simulated equilibrium climate is as warm or cold as it is. Its power lies in analyzing the reasons for the surface temperature difference between two equilibrium climate simulations by quantifying how much surface temperature difference is caused by differences in planetary albedo, effective emissivity, and meridional heat transport. Thus, differences in planetary albedo, effective emissivity, and meridional heat transport are compared on the same scale. Given $\alpha, \epsilon$, and $H$ for MAR and PI, the surface temperature difference between MAR and PI due to a difference in planetary albedo is (Heinemann et al., 2009) 
Table 4. Global annual-mean surface temperature difference between the Marinoan (MAR) and pre-industrial (PI) control simulations as diagnosed by the one-dimensional energy balance model.

\begin{tabular}{lr}
\hline & $\Delta \tau[\mathrm{K}]$ \\
\hline global & -4.6 \\
planetary albedo & -3.5 \\
effective emissivity & -1.3 \\
heat transport & 0.2 \\
\hline
\end{tabular}

$$
\begin{aligned}
& \left.\Delta \tau(\phi)\right|_{\alpha}= \\
& =\sqrt[4]{\frac{1}{\sigma \epsilon(\phi)_{\mathrm{PI}}}\left\{\left(1-\alpha(\phi)_{\mathrm{MAR}}\right) Q(\phi)-H_{\mathrm{PI}}(\phi)\right\}}-\tau_{\mathrm{ebm}}^{\mathrm{PI}}(\phi) .
\end{aligned}
$$

An increase in planetary albedo at some latitude hence translates to a cooling at that latitude, a decrease in planetary albedo to a warming. The surface temperature differences resulting from differences in $\epsilon$ and $H$ are estimated analogously.

At most latitudes, higher planetary albedo and effective emissivity in MAR effect a cooling in MAR compared to PI. These differences are largely due to increased surface albedo, either through increased sea-ice cover (poleward of $45^{\circ} \mathrm{N} / \mathrm{S}$ ) or increased land fraction (between $45^{\circ} \mathrm{S}$ to $20^{\circ} \mathrm{N}$ ), and reduced water vapor content. The shortwave cloud forcing is generally less negative in MAR than PI while the longwave cloud forcing is generally higher. Changes in clouds therefore tend to reduce the cooling of MAR with respect to PI (Table 3). However, there are two notable local exceptions. First, between $30^{\circ} \mathrm{N}$ and $45^{\circ} \mathrm{N}$ surface albedo in MAR is lower than in PI (see Fig. 3), and the increased planetary albedo in this region is caused by locally increased cloud cover and cloud shortwave forcing in MAR compared to PI. Second, in the tropics, effective emissivity is lower in MAR despite reduced water vapor because of a strong increase in the tropical longwave cloud radiative forcing in MAR compared to PI. The latter is associated with more tropical clouds around $300 \mathrm{hPa}$ in MAR compared to PI. Heat transport differences between MAR and PI effect a warming in the tropics and a cooling in midlatitudes. This points at less total heat export from the tropics to midlatitudes (see Fig. 3).

Finally, we quantify how the differences in planetary albedo, effective emissivity and heat transport contribute to the change of global-mean surface temperature. This is done by meridionally averaging the latitudinal contributions (Table 4). We find that two thirds of the global-mean cooling of $4.6 \mathrm{~K}$ from PI to MAR is caused by increased planetary albedo and the remaining one third by a weaker greenhouse effect through increased effective emissivity. The globalmean temperature difference due to differences in the divergence of heat transport is negligible.

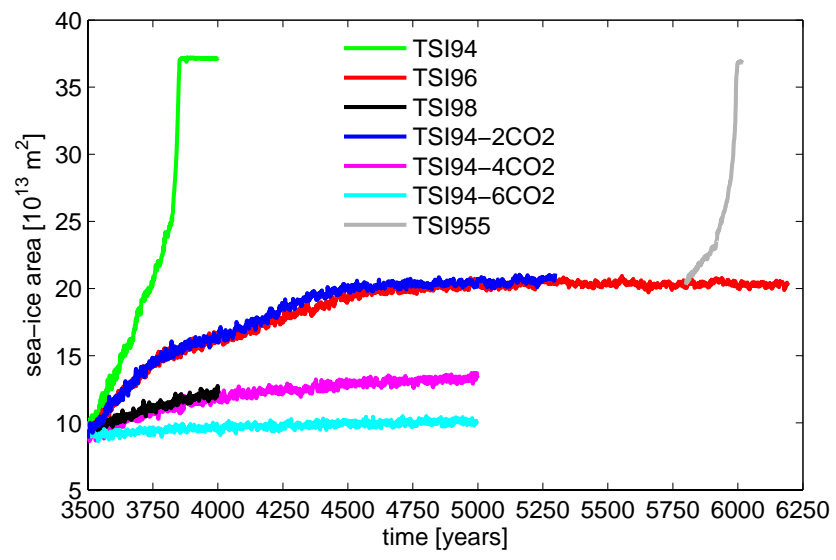

Fig. 5. Time evolution of annual-mean global sea-ice area as a response to an abrupt decrease of total solar irradiance (TSI) and, for some simulations, simultaneous increase of atmospheric carbon dioxide.

\section{Snowball Earth bifurcation point and maximum stable sea-ice cover}

This sections reports on the effect of an abrupt decrease of total solar irradiance and, for some simulations, simultaneous increase of atmospheric carbon dioxide. These simulations enable us to find the Snowball Earth bifurcation point as well as the maximum stable sea-ice cover.

Switching off solar insolation results in global sea-ice cover within 10 years (simulation TSI00, not shown). A reduction of TSI to $94 \%$ of its present-day value leads to a Snowball Earth within 355 years (simulation TSI94, Fig. 5). In TSI94, the sea-ice line is nearly symmetric about the equator during the entire transition, and land snow accumulates in parts of the Southern Hemisphere but nowhere in the Northern Hemisphere. While the increase of the Northern Hemisphere surface albedo is hence solely due to the conversion of open ocean areas to sea ice, snow accumulation on land contributes to the increase of the Southern Hemisphere surface albedo. Interestingly, these two effects combine such that the surface albedo of the two hemispheres increases at roughly the same rate, and meridional heat transports stay largely symmetric about the equator during the entire transition (not shown). Moreover, it is worth noting that in a Snowball Earth state (years 3900 to 3999 of TSI94) annual-mean sea-ice area is slightly below the global ocean area because some ocean regions are seasonally ice-free (the difference is less than $2 \%$ of the global ocean area). However, before one puts trust in the realism of these seasonally sea-ice free regions, at least two model limitations would have to be fixed. First, sea ice would likely grow much thicker if the model's restriction of sea-ice thickness was removed (see Sect. 2). Indeed, in a Snowball Earth state sea-ice thickness is at the cut-off value almost everywhere. Second, missing vertical resolution of the sea-ice model likely results in a too strong 
diurnal cycle of sea-ice temperatures. This permits unrealistic day-time melting of sea ice (Abbot et al., 2010) and probably contributes to the simulation of seasonally ice-free ocean regions in a Snowball Earth state.

In contrast to a reduction of TSI to $94 \%$, decreasing TSI to 96\% does not cause global sea-ice cover (simulation TSI96). In this simulation, sea-ice area stabilizes at $20 \times 10^{13} \mathrm{~m}^{2}$, equivalent to $55 \%$ of the Marinoan ocean surface area.

To further pin down the Marinoan Snowball Earth bifurcation point, we branch off simulation TSI955 from year 5799 of TSI96. In this simulation, TSI is additionally decreased by $6.8 \mathrm{~W} \mathrm{~m}^{-2}$ to $95.5 \%$ of its present-day value. This small additional TSI reduction is sufficient to induce global seaice cover within 201 years. The Snowball Earth bifurcation point, for pre-industrial carbon dioxide, therefore is between 95.5 and $96 \%$ of the present-day TSI.

The fact that we are able to fix the Snowball Earth bifurcation within an uncertainty of $0.5 \%$ of the present-day TSI also enables us to infer the maximum stable sea-ice cover. As shown by TSI96, sea ice can cover 55\% of the ocean surface area without triggering a Snowball Earth instability. At the end of TSI96, the sea-ice line has stabilized at $30^{\circ} \mathrm{N}$ and around $25^{\circ} \mathrm{S}$, respectively (Fig. 6), with sea ice being snow-covered except very close to the sea-ice edge, and snow on land restricted to largely thin snow cover in the southernmost continental regions. The strong sensitivity of this sea-ice line to the small reduction in TSI demonstrates that in ECHAM5/MPI-OM, equilibrium solutions with seaice cover above $55 \%$ are very unlikely.

Falling into a Snowball Earth when TSI is reduced to 94\% can be prevented by an appropriate increase in atmospheric carbon dioxide. Combining a reduction of TSI to $94 \%$ with a doubling of atmospheric carbon dioxide with respect to its pre-industrial level has roughly the same effect on sea-ice area as a reduction of TSI to $96 \%$ (simulation TSI94-2CO2). Therefore, for TSI at $94 \%$ of its present-day value, which is the appropriate value for the Marinoan (Pierrehumbert, 2010; Gough, 1981), the Snowball Earth bifurcation is between one and two times the pre-industrial level of carbon dioxide. Quadrupling carbon dioxide effects an increase of the sea-ice area to $14 \times 10^{13} \mathrm{~m}^{2}$, corresponding to $37 \%$ of the Marinoan ocean surface area (simulation TSI94-4CO2). Increasing carbon dioxide even further to 6 times its preindustrial level almost compensates for the decrease of TSI to $94 \%$ (simulation TSI94-6CO2). After 1000 years, sea-ice area in this simulation is only slightly higher than in the control simulation MAR.

The result that reducing TSI to $94 \%$ and doubling carbon dioxide has roughly the same effect on sea-ice area as reducing TSI to $96 \%$ is consistent with the fact that the radiative forcing of increasing TSI by $2 \%$ (assuming a planetary albedo of 0.351 as simulated for MAR),

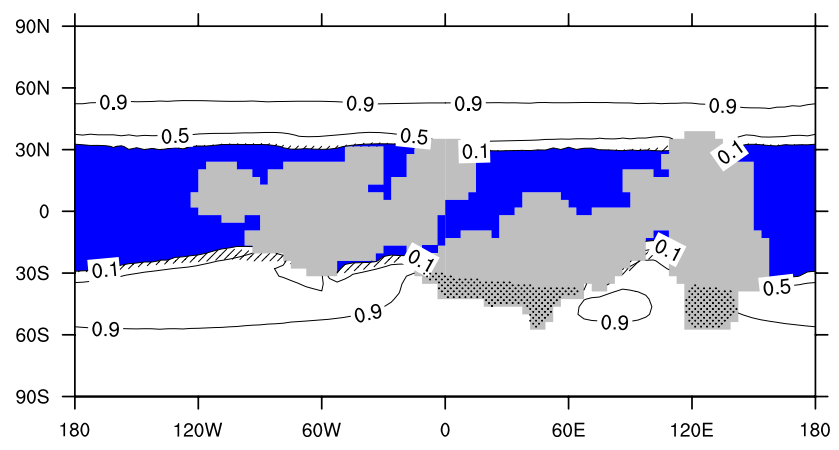

Fig. 6. Sea-ice fraction of simulation TSI96 averaged over years 6000 to 6199 . Contour spacing is 0.4. Open water, defined by sea-ice fraction below 0.1 for this plot, is shown in blue. Areas with snow cover on sea-ice below $0.01 \mathrm{~m}$ water equivalent depth are shaded. Continental areas with snow cover above $0.01 \mathrm{~m}$ water equivalent are stippled.

$$
\begin{aligned}
\operatorname{RF}\left(2 \% \mathrm{TSI}_{0}\right) & =(1-0.351) \cdot 0.02 \frac{1367}{4} \mathrm{~W} \mathrm{~m}^{-2} \\
& =4.4 \mathrm{~W} \mathrm{~m}^{-2},
\end{aligned}
$$

is close to the radiative forcing of doubling carbon dioxide (Myhre et al., 1998),

$\mathrm{RF}\left(2 \times \mathrm{CO}_{2}\right)=5.35 \ln 2 \mathrm{~W} \mathrm{~m}^{-2}=3.7 \mathrm{~W} \mathrm{~m}^{-2}$.

Note that if we took into account that the planetary albedo increases in the course of TSI96 and TSI94-2CO2, we would obtain a lower radiative forcing estimate for the $2 \%$ reduction in TSI, bringing the two estimates slightly closer together. Moreover, the factor of 5.35 used in the radiative forcing estimate of doubling carbon dioxide is valid for present-day conditions but might be different for the Marinoan.

Simulation TSI100 is started from year 3999 of TSI94 with TSI set back to $100 \%$. As one expects, this $6 \%$ increase does not lead to Snowball Earth deglaciation and seaice cover remains global in TSI100 (not shown). This establishes that ECHAM5/MPI-OM exhibits bistability for TSI at its present-day value in the Marinoan setup, as it does for present-day boundary conditions (Marotzke and Botzet, 2007).

\section{Prediction of the Snowball Earth bifurcation point and transition times by a zero-dimensional energy balance model}

For the initiation of a modern Snowball Earth, Voigt and Marotzke (2010) showed that the Snowball Earth bifurcation point and transition times estimated by the atmosphereocean general circulation model are well reproduced by a zero-dimensional energy balance model (Od-EBM) of globalmean ocean potential temperature. We now test if this 0dEBM is equally successful for Marinoan surface boundary conditions. 
By neglecting atmosphere and land and considering the ocean to be perfectly mixed, the Od-EBM of Voigt and Marotzke (2010) predicts the evolution of global-mean ocean potential temperature, $\theta$, in response to a TSI decrease according to

$c \frac{d \theta}{d t}=\frac{(1-\alpha)}{4} \mathrm{TSI}-\epsilon \sigma \theta^{4}$,

where $c=205 \times 10^{8} \mathrm{JK}^{-1} \mathrm{~m}^{-2}$ is the ocean heat capacity per unit surface area, $\alpha$ can be thought of as the global-mean planetary albedo, and $\epsilon$ represents the greenhouse effect (not to be confused with $\alpha(\phi)$ and $\epsilon(\phi)$ of the one-dimensional energy balance model of Sect. 3.2). Note that by taking into account shortwave radiation and the greenhouse effect, this Od-EBM is a significant extension of the Od-EBM of Galeotti et al. (2004) developed for the K-T boundary.

In the Od-EBM, a Snowball Earth is defined by $\theta$ equal to the freezing temperature of sea water, $\theta_{\mathrm{f}}=271.25 \mathrm{~K}$. The Od-EBM furthermore assumes that the ratio $(1-\alpha) / \epsilon$ is independent of $\theta$. This ratio is fixed by requiring that MAR is an equilibrium solution of Eq. (3) for today's value of TSI, $\mathrm{TSI}_{0}$,

$\frac{1-\alpha}{\epsilon}=4 \sigma \frac{\theta_{\mathrm{MAR}}^{4}}{\mathrm{TSI}_{0}} \simeq 0.9392$.

The Od-EBM's estimate of the Snowball Earth bifurcation point, $\mathrm{TSI}_{\mathrm{c}}$, is defined as that TSI value at which the ocean potential temperature, after the sudden decrease of TSI, equilibrates at the freezing temperature of sea water. This yields

$\mathrm{TSI}_{\mathrm{c}}=\frac{4 \sigma \epsilon}{(1-\alpha)} \theta_{\mathrm{f}}^{4}=\left(\frac{\theta_{\mathrm{f}}}{\theta_{\mathrm{MAR}}}\right)^{4} \mathrm{TSI}_{0}$.

Inserting $\theta_{\text {MAR }}$ yields a Od-EBM estimate of the Snowball Earth bifurcation point of $95.63 \% \mathrm{TSI}_{0}$. This is in intriguing agreement with the 95.5 to $96 \%$ range found with the atmosphere-ocean general circulation model.

The 0d-EBM's estimate of the Snowball Earth bifurcation point follows from the assumption that the ratio $(1-\alpha) / \epsilon$ is the same for $\mathrm{TSI}_{0}$ and $\mathrm{TSI}_{\mathrm{c}}$, and all TSI values in between. Since a TSI reduction triggers sea-ice expansion and by this an increased planetary albedo, this assumption implies a decrease of $\epsilon$ with reduced TSI. At first glance, the latter seems incompatible with decreased atmospheric water vapor in a colder climate. However, this conflict is resolved by acknowledging that in order to compare the 0dEBM parameter $\epsilon$ with the effective emissivity that is diagnosed from the atmosphere-ocean general circulation model, $\epsilon_{\mathrm{gcm}}$, we need to incorporate the form factor $(\mathrm{SST} / \theta)^{4}$ (Voigt and Marotzke, 2010). This factor takes into account that the 0d-EBM parameterizes longwave radiation energy loss through the global-mean ocean potential temperature instead of global-mean sea surface temperature SST. This yields

$\epsilon=\epsilon_{\mathrm{gcm}}\left(\frac{\mathrm{SST}}{\theta}\right)^{4}$.
While the effective emissivity $\epsilon_{\mathrm{gcm}}$ increases with decreased TSI, the 0d-EBM parameter $\epsilon$ can still decrease because decreased TSI also reduces ocean stratification (Voigt and Marotzke, 2010). This somewhat justifies the assumption of a constant ratio $(1-\alpha) / \epsilon$, but it is still surprising that this assumption yields a successful prediction of the Snowball Earth bifurcation point.

Voigt and Marotzke (2010) have solved Eq. (3) in order to find the transition time to a Snowball Earth. While integrating Eq. (3) is readily done (Voigt, 2010), the fact that the considered values of $\theta$ are close to $\theta_{\mathrm{f}}$ suggests the linearization of Eq. (3) at $\theta_{\mathrm{f}}$. Doing so allows us to derive a much simpler but even better estimate for the transition times as obtained by solving the nonlinear Eq. (3).

If we write

$\theta(t, \mathrm{TSI})=\theta_{\mathrm{f}}+T(t, \mathrm{TSI})$

where $T$ denotes the deviation of global-mean ocean potential temperature from the freezing point of sea water, Eq. (3) becomes an ordinary linear differential equation in $T$,

$\gamma \frac{d T}{d t}(t, \mathrm{TSI})=T_{\mathrm{r}}(\mathrm{TSI})-T(t, \mathrm{TSI})$,

with

$\gamma=\frac{c}{4 \sigma \epsilon \theta_{\mathrm{f}}^{3}}$

and

$T_{\mathrm{r}}(\mathrm{TSI})=\frac{1-\alpha}{16 \sigma \epsilon \theta_{\mathrm{f}}^{3}} \mathrm{TSI}-\frac{\theta_{\mathrm{f}}}{4}$.

We fix $T_{\mathrm{r}}$ by Eq. (4),

$T_{\mathrm{r}}(\mathrm{TSI})=\frac{\mathrm{TSI}}{4 \mathrm{TSI}_{0}} \frac{\theta_{\mathrm{MAR}}^{4}}{\theta_{\mathrm{f}}^{3}}-\frac{\theta_{\mathrm{f}}}{4}$,

This implies that $T_{\mathrm{MAR}}=\theta_{\mathrm{MAR}}-\theta_{\mathrm{f}}$ is not a strict equilibrium solution of the linearized Od-EBM Eq. (5) for $\mathrm{TSI}_{0}$, but it is readily proven that $d T_{\mathrm{MAR}} / d t\left(t, \mathrm{TSI}_{0}\right)$ with this choice of $T_{\mathrm{r}}$ only contains terms that are of quadratic or higher order in $T_{\text {MAR }}$, showing that $T_{\text {MAR }}$ is an equilibrium solution of the linearized 0d-EBM within the validity of the linear approximation. $\gamma$ is fixed by setting $\epsilon$ to the effective emissivity of MAR, $\epsilon_{\text {MAR }}=0.594$ (Table 3). Incorporating the initial condition $T(t=0, \mathrm{TSI})=T_{\mathrm{MAR}}$, Eq. (5) is solved by

$T(t, \mathrm{TSI})=T_{\mathrm{r}}(\mathrm{TSI})+\left\{T_{\mathrm{MAR}}-T_{\mathrm{r}}(\mathrm{TSI})\right\} \exp (-t / \gamma)$.

The transition time to a Snowball Earth estimated with the linearized Od-EBM, $t_{\mathrm{f}}^{\text {lin }}(\mathrm{TSI})$, is defined by $T\left(t_{\mathrm{f}}, \mathrm{TSI}\right)=0$. We obtain

$t_{\mathrm{f}}^{\operatorname{lin}}(\mathrm{TSI})=\gamma \ln \frac{T_{\mathrm{r}}(\mathrm{TSI})-T_{\mathrm{MAR}}}{T_{\mathrm{r}}(\mathrm{TSI})}$.

When the insolation is set to zero, the linearized Od-EBM yields a transition time of 11 years (Fig. 7). This is in very 
close agreement with the GCM, in particular since no explicit tuning of $\epsilon$ is applied to the linearized version of 0d-EBM, in contrast to its nonlinear version. The transition time for $\mathrm{TSI}=94 \% \mathrm{TSI}_{0}$ is 311 years. While this is less than what the GCM gives (355 years), this is a reasonable estimate in the light of the 0d-EBM's simplifications. Note that the nonlinear 0d-EBM yields a slightly shorter estimate (264 years) in this case, but the transition time of the nonlinear 0d-EBM would be hardly distinguishable from that of the linear version when plotted in Fig. 7.

\section{Discussion}

In the state-of-the-art atmosphere-ocean general circulation model ECHAM5/MPI-OM, changing the surface boundary conditions from present-day to Marinoan ( $635 \mathrm{Ma})$ induces a global-mean cooling of $4.6 \mathrm{~K}$ for present-day total solar irradiance and pre-industrial greenhouse gas levels. This cooling is in line with what we expect from moving the continents from high to low latitudes according to the Marinoan reconstruction. While global-mean surface background albedo is the same in the Marinoan and the present-day setup, the movement of continents redistributes background surface albedo across the globe. The larger tropical land fraction in the Marinoan yields a higher low latitude (background) surface albedo in the Marinoan than today and thereby results in a cooling of the climate by virtue of the larger incoming shortwave radiation in low latitudes. Nevertheless, we note that the Marinoan surface boundary conditions are distinct from the present-day surface boundary conditions in more aspects than the location of continents, and that the gravity wave drag was active in the pre-industrial control simulation but disabled for the Marinoan simulations. We cannot judge to which extent, for example, differences in vegetation cover and surface roughness length contribute to the cooling. It is not even clear that they contribute to the cooling at all, and many more simulations would be needed to quantify the effect of individual differences of the present-day and Marinoan surface boundary conditions on the simulated cooling.

This cooling allows a Snowball Earth to be initiated more easily for Marinoan than for present-day surface boundary conditions. For the latter a reduction of TSI to $94 \%$ did not result in a Snowball Earth (Voigt and Marotzke, 2010), whereas we find it to be sufficient for the Marinoan setup. To the extent that the change of the continental distribution is the main cause for this cooling in our simulations, our study hence supports the notion that low-latitude continents facilitate global glaciation (Kirschvink, 1992). Our study confirms the result of Lewis et al. (2003), but is in disagreement with Pollard and Kasting (2004) and Poulsen et al. (2002), suggesting that more studies are needed to clarify the role of continents for Snowball Earth initiation. In the study of Poulsen et al. (2002) with the Fast Ocean Atmosphere Model (FOAM), global-mean surface temperature is

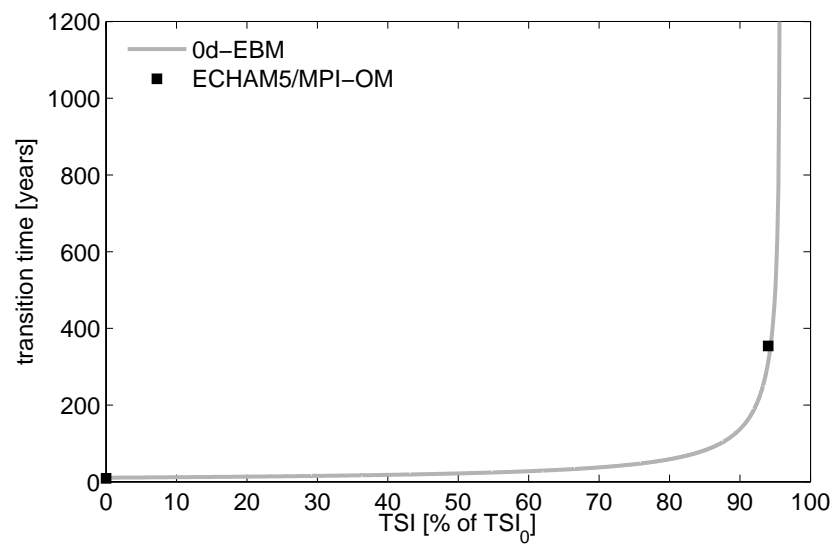

Fig. 7. Transition time to a Snowball Earth in dependence of total solar irradiance as estimated by the linearized zero-dimensional energy balance model of global-mean ocean potential temperature (gray) and found by ECHAM5/MPI-OM (black squares). Total solar irradiance is given in percentage of the present-day value $\mathrm{TSI}_{0}$.

about $5 \mathrm{~K}$ higher when an equatorial supercontinent instead of Southern Hemisphere (SH) continents is used. According to Poulsen et al. (2002), the lower global-mean surface temperature for $\mathrm{SH}$ continents results from a cooling of the SH through less shortwave absorption and less positive highlatitude cloud forcing while $\mathrm{NH}$ temperatures do not differ between the setups with the SH continent and an equatorial supercontinent.

Sea-ice expansion during the transition to a Snowball Earth with Marinoan boundary conditions is roughly symmetric about the equator, despite asymmetry in the continental configuration. In contrast, sea-ice advance during the transition to a Snowball Earth with present-day boundary conditions was highly asymmetric (Voigt and Marotzke, 2010). The main difference is that snow accumulates on land with Marinoan boundary conditions such that the average albedo of the two hemispheres is roughly the same as sea ice advances, but this does not occur with present-day boundary conditions. Our results therefore underscore that continental configuration can play an important role in determining the details of the specific sea-ice expansion route taken to a Snowball Earth.

ECHAM5/MPI-OM does not exhibit states with near complete sea-ice cover but open equatorial water as the climate system becomes unstable for sea-ice cover above 55\% of the ocean surface area. Note that this is consistent with FOAM (Poulsen and Jacob, 2004). While one might suspect that Chandler and Sohl (2000) and Micheels and Montenari (2008) found such solutions because their models neglected ocean dynamics, Pierrehumbert et al. (2011) proposed that the sea-ice and snow albedo parameterization used in these studies might lead to those almost but not completely sea-ice covered states (Pierrehumbert et al., 2011). For the maximum stable sea-ice extent most parts of the continents are 
still too warm to allow perennial snow cover (Figs. 6 and 8). Even where snow cover is possible at the poleward tips of the continents, it mainly stays at depth below $0.1 \mathrm{~m}$ water equivalent. We therefore do not find indications for Slushball Earth solutions although our simulations do not allow us to exclude their existence since we neglect mountains in this study. Through lapse-rate effects on temperature and by triggering up-slope precipitation, mountains might promote land snow accumulation and hence permit land glacier formation directly in tropical locations (Pollard and Kasting, 2004), or land glaciers might form in higher latitudes and then flow to the tropics (Liu and Peltier, 2010). Also, Pollard and Kasting (2004) and Liu and Peltier (2010) suggested that the continental configuration is important for the formation of land glaciers.

Despite the crucial importance of ocean dynamics for Snowball Earth initiation (Poulsen et al., 2001), the only other atmosphere-ocean general circulation model used to study Snowball Earth initiation is FOAM. Our conclusions differ from those drawn using FOAM in a number of ways. First, Poulsen (2003) showed that FOAM does not initiate a Snowball at TSI decreased to $93 \%$ of its present-day value and $\mathrm{CO}_{2}$ and $\mathrm{CH}_{4}$ set to $140 \mathrm{ppmv}$ and $700 \mathrm{ppmb}$, respectively. This is sometimes cited as evidence that atmosphereocean general circulation models cannot exhibit a runaway ice-albedo feedback in the Neoproterozoic (Ridgwell and Kennedy, 2004; Chumakov, 2008), even though Poulsen and Jacob (2004) corrected this misconception by showing that FOAM does exhibit a runaway ice-albedo feedback when TSI is further reduced to $91 \%$. Our results further refute this misconception.

Second, although both FOAM and ECHAM5/MPI-OM exhibit a runaway ice-albedo feedback, Snowball initiation requires a much stronger forcing in FOAM than in ECHAM5/MPI-OM. The difference in the initiation behavior between FOAM and ECHAM5/MPI-OM probably has numerous origins, including the models' treatment of seaice, oceanic, and atmospheric processes, the albedo of land, sea ice, and snow, and the continental configuration, with the latter exerting strong influence on the Snowball Earth bifurcation point in ECHAM5/MPI-OM as shown in this study. While it is beyond the scope of this study to identify the model differences responsible for the much easier Snowball Earth initiation in ECHAM5/MPI-OM than in FOAM, we note that the SNOWMIP project described in Pierrehumbert et al. (2011) has made such an attempt by comparing the Snowball Earth initiation behavior of FOAM and ECHAM5 in an aquaplanet setup with several sea-ice and snow albedo parameterizations (see Pierrehumbert et al., 2011 for details). SNOWMIP has illustrated that the initiation behavior of climate models is strongly controlled by the models' assumptions about snow and sea-ice albedo, which calls for future research to figure out which albedos are appropriate in Snowball Earth conditions. Furthermore, SNOWMIP has demonstrated that differences in the simulation of the atmospheric

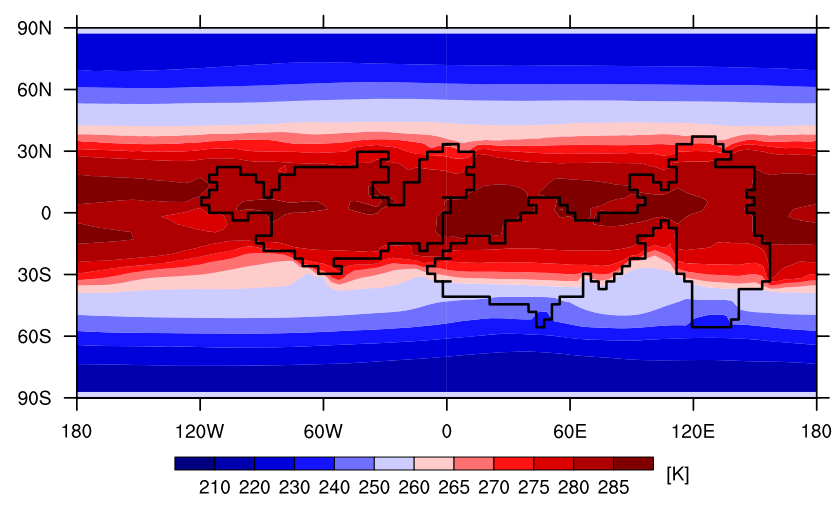

Fig. 8. Annual-mean surface temperature in K of simulation TSI96 averaged over years 6000 to 6199 . Contour spacing is $5 \mathrm{~K}$ above $260 \mathrm{~K}$ and $10 \mathrm{~K}$ below $260 \mathrm{~K}$.

circulation and clouds significantly contribute to the different initiation behavior of FOAM and ECHAM5/MPI-OM (Pierrehumbert et al., 2011). That said, since it is possible that other atmosphere-ocean general circulation models are either more resistant or more prone to Snowball Earth initiation than ECHAM5/MPI-OM, studies with different atmosphereocean general circulation models are needed to judge the model dependence of our findings and to put our results into perspective.

There are no serious doubts that total solar irradiance in the Marinoan was around 94\% of its present-day value (Pierrehumbert, 2010; Gough, 1981). In contrast, Marinoan atmospheric carbon dioxide values are poorly, if at all, constrained (Peltier, 2003). Moreover, the comparison of the Snowball Earth bifurcation point between models is rendered difficult by the use of different continents and albedo values. Despite these issues, our study demonstrates that Snowball Earth initiation for Marinoan total solar irradiance (94\% of the present-day value) in the most sophisticated climate model hitherto applied is possible at similar or even higher carbon dioxide levels than in simpler models without ocean dynamics (Donnadieu et al., 2004; Micheels and Montenari, 2008; Chandler and Sohl, 2000; Pollard and Kasting, 2004). This implies that models that calculate ocean heat transport dynamically are not necessarily more resistant to Snowball Earth initiation than models that do not incorporate ocean dynamics but use a specified ocean heat transport.

Because of uncertainties in the boundary conditions as well as in important parameters and processes, our study does not demonstrate that a Snowball Earth indeed occurred in the Marinoan. Nevertheless, by showing that Snowball Earth initiation in the most sophisticated model ever used for this purpose is easier than in some previous modelling studies, we explicitly demonstrate that difficulties with Snowball Earth initiation in some models should not be interpreted as evidence against the Snowball Earth hypothesis. We conclude that concerning Snowball Earth initiation, there 
is currently no conflict between climate modelling and the Snowball Earth hypothesis.

\section{Conclusions}

Using the state-of-the-art atmosphere-ocean general circulation model ECHAM5/MPI-OM to study the initiation of a Marinoan Snowball Earth and comparing these simulations with a previous study with present-day surface boundary conditions (Voigt and Marotzke, 2010), we conclude the following:

1. Changing surface boundary conditions from presentday to Marinonan induces a global-mean cooling of $4.6 \mathrm{~K}$. Our study supports the notion that low-latitude continents facilitate Snowball Earth initiation.

2. For pre-industrial atmospheric carbon dioxide, the Snowball Earth bifurcation point is between 95.5 and $96 \%$ of the present-day value of total solar irradiance (TSI). For TSI set to its Marinoan value (94\% of the present-day TSI), a Snowball Earth is prevented by doubling atmospheric carbon dioxide with respect to its pre-industrial level. This refutes previous findings that Snowball Earth initiation would require much stronger forcings.

3. The reduction in total solar irradiance that leads to a Snowball Earth bifurcation with Marinoan boundary conditions can be predicted by a zero-dimensional energy balance model given the equilibrium global mean ocean potential temperature for present-day total solar irradiance.

4. We do not find stable states with sea-ice cover of more than $55 \%$ of the ocean surface area, which is consistent with what was previously found for present-day surface boundary conditions. ECHAM5/MPI-OM therefore does not exhibit states with near-complete sea-ice cover but open equatorial waters.

5. Even with 55\% sea-ice cover, land glaciers cannot form. Therefore, our simulations do not support the Slushball hypothesis, with the important caveat that mountains are not included in our study.

\section{Appendix A}

\section{Energy fluxes at the top of atmosphere and at the surface}

Energy conservation requires that for an atmosphere in equilibrium, the global-mean energy flux at the top of atmosphere, $F_{\text {toa }}$ (given by the sum of net incoming shortwave radiation and outgoing longwave radiation), must equal the

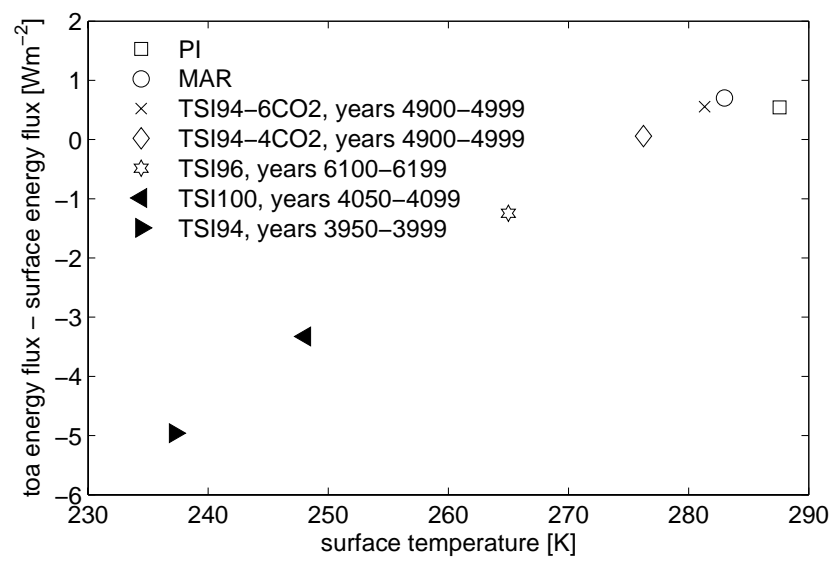

Fig. A1. Difference between the top of atmosphere energy flux and the surface energy flux in dependence of global-mean surface temperature. Positive values suggest the existence of an artificial energy sink in the atmosphere model, negative values the existence of an artificial energy source.

global-mean energy flux at the surface, $F_{\text {sfc }}$ (given by the sum of surface shortwave and longwave radiation and latent and sensible heat fluxes). For the Marinoan control simulation MAR, the top of atmosphere energy flux is $0.7 \mathrm{~W} \mathrm{~m}^{-2}$ larger than the surface energy flux (Fig. A1). This imbalance is close to the $0.5 \mathrm{~W} \mathrm{~m}^{-2}$ imbalance found for the preindustrial control simulation PI and is in the "accepted" range of $\pm 1 \mathrm{~W} \mathrm{~m}^{-2}$ (E. Roeckner, personal communication, 2010).

In contrast, the diagnosed TOA energy flux differs from the surface energy flux by $5 \mathrm{~W} \mathrm{~m}^{-2}$ in an equilibrium Snowball Earth state for total solar irradiance reduced to $94 \%$ of its today's value (Fig. A1). This means that more energy is leaving the atmosphere at its top than entering the atmosphere at its surface. If we use the global integral of atmospheric energy content of today's atmosphere, $H_{\text {atm }}=256 \times 10^{7} \mathrm{~J} \mathrm{~m}^{-2}$ (Peixoto and Oort, 1992), as an estimate for the atmospheric energy content of the equilibrium Snowball Earth atmosphere, we find that this imbalance accumulates to the total atmospheric energy content within

$\frac{H_{\mathrm{atm}}}{F_{\mathrm{toa}}-F_{\mathrm{sfc}}} \simeq 16 \mathrm{a}$.

Moreover, the imbalance between the diagnosed top of atmosphere and the surface energy fluxes exhibits a roughly linear dependence on global-mean surface temperature (Fig. A1).

There are at least two issues that could explain the diagnosed imbalance. First, ECHAM5/MPI-OM allows for fractional sea-ice cover of a grid cell, but the model's diagnosis of the surface energy fluxes might be incorrect in this case (E. Roeckner, personal communication, 2010). Since even in a Snowball Earth state some small percentage of the ocean is seasonally ice free; this may explain the imbalance. Also, this may explain why the imbalance grows with decreased surface temperature and thereby increased sea-ice 
cover, because increased sea-ice cover might go along with more fractional sea-ice covered grid cells. Second, if the model diagnoses surface energy fluxes correctly for grid cells with fractional sea-ice cover, then the imbalance in TOA and surface energy fluxes requires the existence of an artificial energy source. One could imagine that this source is introduced by the model's physics parameterizations, which are tuned to the present-day climate and whose behavior in much colder climates is untested.

We have reason to believe that both issues contribute to the diagnosed imbalance, and that they introduce errors that compensate in some but not all cases. This is based on the following ECHAM5 simulations in aquaplanet mode. In the SNOWMIP runs presented in Pierrehumbert et al. (2011), ECHAM5 is coupled to a mixed-layer ocean and is not allowed to have fractional sea-ice cover. While not reported in Pierrehumbert et al. (2011), TOA and surface energy fluxes in none of the equilibrated ECHAM5 SNOWMIP runs differ by more than $0.6 \mathrm{~W} \mathrm{~m}^{-2}$. This seems to be strong support for the first explanation, but when ECHAM5 is run with fixed SSTs of $272 \mathrm{~K}$ the TOA energy flux is $5 \mathrm{~W} \mathrm{~m}^{-2}$ smaller than the surface energy flux, implying an artificial energy source of $5 \mathrm{~W} \mathrm{~m}^{-2}$ in this simulation. This imbalance clearly can not be due to incorrectly diagnosed surface fluxes for fractionally sea-ice covered grid cells since there is no sea ice at all in this simulation.

A detailed investigation of the reasons for the diagnosed imbalance is desirable, but beyond the scope of this article. We note that a similar imbalance was diagnosed for the equilibrium Snowball Earth atmosphere under presentday surface boundary conditions with ECHAM5/MPI-OM, although it was not mentioned in Voigt and Marotzke (2010). Moreover, Romanova et al. (2006) reported that the presentday control climate of the atmosphere general circulation model of intermediate complexity PUMA shows an imbalance of $3.5 \mathrm{~W} \mathrm{~m}^{-2}$, but Romanova et al. (2006) did not analyze the reasons for this.

Acknowledgements. We thank Malte Heinemann and Helmuth Haak for help with implementing the Marinoan surface boundary conditions, and Michael Botzet for the internal review at MPI-M. We appreciate the comments of three anonymous reviewers. This work was supported by the Max Planck Society and the International Max Planck Research School on Earth System Modelling. In particular, we thank the IMPRS-ESM Guest and Exchange Program for financial support for a visit of D. S. A. to Hamburg and for a visit of A. V. to the University of Chicago, during which part of this article was written. D. S. A. and R. T. P. were supported by the Canadian Institute for Advanced Research. D. S. A. was supported by a T. C. Chamberlin Fellowship of the University of Chicago. All simulations were performed at the German Climate Computing Center (DKRZ) in Hamburg, Germany.
The service charges for this open access publication have been covered by the Max Planck Society.

Edited by: H. Goosse

\section{References}

Abbot, D. S., Eisenman, I., and Pierrehumbert, R. T.: The importance of ice resolution for Snowball climate and deglaciation, J. Climate, 23, 6100-6109, doi:10.1175/2010JCLI3693.1, 2010.

Baum, S. K. and Crowley, T. J.: GCM response to late precambrian (similar to $590 \mathrm{Ma}$ ) ice-covered continents, Geophys. Res. Lett., 28(4), 583-586, doi:10.1029/2000GL011557, 2001.

Berger, A. L.: Long term variations of daily insolation and Quaternary climatic changes, J. Atmos. Sci., 35(12), 2362-2367, 1978.

Bretagnon, P. and Francou, G.: Planetary theories in rectangular and spherical variables - VSOP 87 Solutions, Astron. Astrophys., 202(1-2), 309-315, 1988.

Budyko, M. I.: Effect of solar radiation variations on climate of Earth, Tellus, 21(5), 611-619, 1969.

Chandler, M. A. and Sohl, L. E.: Climate forcings and the initiation of low-latitude ice sheets during the Neoproterozoic Varanger glacial interval, J. Geophys. Res.-Atmos., 105(D16), 2073720756, doi:10.1029/2000JD900221, 2000.

Chumakov, N.: A problem of total glaciations on the Earth in the Late Precambrian, Stratigr. Geol. Correl., 16(2), 107-119, doi:10.1134/S0869593808020019, 2008.

Donnadieu, Y., Ramstein, G., Fluteau, F., Roche, D., and Ganopolski, A.: The impact of atmospheric and oceanic heat transports on the sea-ice-albedo instability during the Neoproterozoic, Clim. Dynam., 22(2-3), 293-306, doi:10.1007/s00382003-0378-5, 2004.

Evans, D. A. D.: Stratigraphic, geochronological, and paleomagnetic constraints upon the Neoproterozoic climatic paradox, Am. J. Sci., 300(5), 347-433, doi:10.2475/ajs.300.5.347, 2000.

Fischer, N. and Jungclaus, J. H.: Effects of orbital forcing on atmosphere and ocean heat transports in Holocene and Eemian climate simulations with a comprehensive Earth system model, Clim. Past, 6, 155-168, doi:10.5194/cp-6-155-2010, 2010.

Fortuin, J. P. F. and Kelder, H.: An ozone climatology based on ozonesonde and satellite measurements, J. Geophys. Res.Atmos., 103(D24), 31709-31734, doi:10.1029/1998JD200008, 1998.

Galeotti, S., Brinkhuis, H., and Huber, M.: Records of postCretaceous-Tertiary boundary millennial-scale cooling from the western Tethys: A smoking gun for the impact-winter hypothesis?, Geology, 32, 529-532, doi:10.1130/G20439.1, 2004.

Gough, D. O.: Solar interior structure and luminosity variations, Sol. Phys., 74(1), 21-34, 1981.

Hagemann, S.: MPI-Report 336: An improved land surface parameter dataset for global and regional climate models, Tech. rep., Max Planck Institute for Meteorology, Hamburg, Germany, 2002.

Heinemann, M., Jungclaus, J. H., and Marotzke, J.: Warm Paleocene/Eocene climate as simulated in ECHAM5/MPI-OM, Clim. Past, 5, 785-802, doi:10.5194/cp-5-785-2009, 2009.

Hibler, W. D.: Dynamic thermodynamic sea ice model, J. Phys. Oceanogr., 9(4), 815-846, 1979. 
Hoffman, P. F. and Schrag, D. P.: The snowball Earth hypothesis: testing the limits of global change, Terra Nova, 14(3), 129-155, doi:10.1046/j.1365-3121.2002.00408.x, 2002.

Hoffman, P. F., Kaufman, A. J., Halverson, G. P., and Schrag, D. P.: A Neoproterozoic snowball earth, Science, 281(5381), 13421346, doi:10.1126/science.281.5381.1342, 1998.

Hyde, W. T., Crowley, T. J., Baum, S. K., and Peltier, W. R.: Neoproterozoic 'snowball Earth' simulations with a coupled climate/ice-sheet model, Nature, 405(6785), 425-429, doi:10.1038/35013005, 2000.

Kerr, R. A.: Snowball Earth has melted back to a profound wintry mix, Science, 327(5970), 1186, doi:10.1126/science.327.5970.1186, 2010.

Kirschvink, J. L.: The Proterozoic Biosphere, in: Late Proterozoic low-latitude global glaciation: The snowball Earth, edited by: Schopf, J. W. and Klein, C., Cambridge University Press, Cambridge, UK, 51-52, 1992.

Le Hir, G., Donnadieu, Y., Godderis, Y., Pierrehumbert, R. T., Halverson, G. R., Macouin, M., Nedelec, A., and Ramstein, G.: The snowball Earth aftermath: Exploring the limits of continental weathering processes, Earth Planet. Sc. Lett., 277(3-4), 453463, doi:10.1016/j.epsl.2008.11.010, 2009.

Lewis, J. P., Weaver, A. J., Johnston, S. T., and Eby, M.: Neoproterozoic "snowball Earth": Dynamic sea ice over a quiescent ocean, Paleoceanography, 18(4), 1092, doi:10.1029/2003PA000926, 2003.

Lewis, J. P., Weaver, A. J., and Eby, M.: Snowball versus slushball Earth: Dynamic versus nondynamic sea ice?, J. Geophys. Res.Oceans, 112(C11), C11014, doi:10.1029/2006JC004037, 2007.

Liu, Y. and Peltier, W. R.: A carbon cycle coupled climate model of Neoproterozoic glaciation: Influence of continental configuration on the formation of a "soft snowball", J. Geophys. Res.Atmos., 115, D17111, doi:10.1029/2009JD013082, 2010.

Lott, F. and Miller, M. J.: A new subgrid-scale orographic drag parametrization: Its formulation and testing, Q. J. Roy. Meteor. Soc., 123(537), 101-127, doi:10.1002/qj.49712353704, 1997.

Lubick, N.: Palaeoclimatology: Snowball fights, Nature, 417(6884), 12-13, doi:10.1038/417012a, 2002.

Macdonald, F. A., Schmitz, M. D., Crowley, J. L., Roots, C. F., Jones, D. S., Maloof, A. C., Strauss, J. V., Cohen, P. A., Johnston, D. T., and Schrag, D. P.: Calibrating the Cryogenian, Science, 327(5970), 1241-1243, doi:10.1126/science.1183325, 2010.

Marotzke, J. and Botzet, M.: Present-day and ice-covered equilibrium states in a comprehensive climate model, Geophys. Res. Lett., 34, L16704, doi:10.1029/2006GL028880, 2007.

Marshall, J., Ferreira, D., Campin, J. M., and Enderton, D.: Mean climate and variability of the atmosphere and ocean on an aquaplanet, J. Atmos. Sci., 64(12), 4270-4286, doi:10.1175/2007JAS2226.1, 2007.

Marsland, S. J., Haak, H., Jungclaus, J. H., Latif, M., and Roske, F.: The Max-Planck-Institute global ocean/sea ice model with orthogonal curvilinear coordinates, Ocean Model., 5(2), 91-127, doi:10.1016/S1463-5003(02)00015-X, 2003.

Micheels, A. and Montenari, M.: A snowball Earth versus a slushball Earth: Results from Neoproterozoic climate modeling sensitivity experiments, Geosphere, 4(2), 401-410, doi:10.1130/GES00098.1, 2008.
Myhre, G., Highwood, E. J., Shine, K. P., and Stordal, F.: New estimates of radiative forcing due to well mixed greenhouse gases, Geophys. Res. Lett., 25(14), 2715-2718, doi:10.1029/98GL01908, 1998.

Peixoto, J. P. and Oort, A. H.: Physics of Climate, American Institute of Physics, New York, USA, 1992.

Peltier, W. R.: Earth System History, in: Encyclopedia of Global Environmental Change, Volume 1, The Earth System: Physical and Chemical Dimensions of Global Environmental Change, edited by: MacCracken, M. C. and Perry, J. S., John Wiley \& Sons, Hoboken, NJ, USA, 31-60, 2003.

Peltier, W. R., Tarasov, L., Vettoretti, G., and Solheim, L. P.: Climate dynamics in deep time: Modeling the "Snowball bifurcation" and assessing the plausibility of its occurrence, in: The Extreme Proterozoic: Geology, Geochemistry and Climate, Geoph. Monog. Series, 146, edited by: Jenkins, G. S., McMenamin, M. A., McKay, C. P., and Sohl, L., AGU Washington, DC, 107-124, 2004.

Pierrehumbert, R. T.: Principles of Planetary Climate, Cambridge University Press, Cambridge, UK, 2010.

Pierrehumbert, R. T., Abbot, D. S., Voigt, A., and Koll, D.: Climate of the Neoproterozoic, Annu. Rev. Earth Pl. Sc., accepted, 2011.

Pollard, D. and Kasting, J. F.: Climate-Ice Sheet Simulations of Neoproterozoic Glaciation Before and After Collapse to Snwowball Earth, in: The Extreme Proterozoic: Geology, Geochemistry and Climate, Geoph. Monog. Series, 146, edited by: Jenkins, G. S., McMenamin, M. A., McKay, C. P., and Sohl, L., AGU Washington, DC, 91-105, 2004.

Poulsen, C. J.: Absence of a runaway ice-albedo feedback in the Neoproterozoic, Geology, 31(6), 473-476, 2003.

Poulsen, C. J. and Jacob, R. L.: Factors that inhibit snowball Earth simulation, Paleoceanography, 19(4), PA4021, doi:10.1029/2004PA001056, 2004.

Poulsen, C. J., Pierrehumbert, R. T., and Jacob, R. L.: Impact of ocean dynamics on the simulation of the Neoproterozoic "snowball Earth", Geophys. Res. Lett., 28(8), 1575-1578, doi:10.1029/2000GL012058, 2001.

Poulsen, C. J., Jacob, R. L., Pierrehumbert, R. T., and Huynh, T. T.: Testing paleogeographic controls on a Neoproterozoic snowball Earth, Geophys. Res. Lett., 29(11), 1515, doi:10.1029/2001GL014352, 2002.

Reichler, T. and Kim, J.: How well do coupled models simulate today's climate?, B. Am. Meteorol. Soc., 89(3), 303-311, doi:10.1175/BAMS-89-3-303, 2008.

Ridgwell, A. and Kennedy, M. J.: Secular changes in the importance of neritic carbonate deposition as a control on the magnitude and stability of Neoproterozoic ice ages, in: The Extreme Proterozoic: Geology, Geochemistry and Climate, Geoph. Monog. Series, 146, edited by: Jenkins, G. S., McMenamin, M. A. S., McKay, C. P., and Sohl, L., AGU Washington, DC, 55-72, 2004.

Roeckner, E.: EH5-T31L19_MPIOM-GR3.0L40 PIcntrl, World Data Center for Climate, CERA-DB "EH5-T31L19_OMGR3.0L40_CTL", http://cera-www.dkrz.de/WDCC/ui/Compact. jsp?acronym=EH5-T31L19_OM-GR3.0L40_CTL (last access: January 2010), 2007. 
Roeckner, E., Bäuml, G., Bonaventura, L., Brokopf, R., Esch, M., Giorgetta, M., Hagemann, S., Kirchner, I., Kornblueh, L., Manzini, E., Rhodin, A., Schlese, U., Schulzweida, U., and Tompkins, A.: The atmospheric general circulation model ECHAM5, part I: Model description, Tech. rep., Max Planck Institute for Meteorology, Hamburg, Germany, 2003.

Romanova, V., Lohmann, G., and Grosfeld, K.: Effect of land albedo, $\mathrm{CO}_{2}$, orography, and oceanic heat transport on extreme climates, Clim. Past, 2, 31-42, doi:10.5194/cp-2-31-2006, 2006.

Sellers, W. D.: A global climate model based on the energy balance of the Earth-atmosphere system, J. Appl. Meteorol., 8, 392-400, 1969.

Semtner, A. J.: Model for thermodynamic growth of sea ice in numerical investigations of climate, J. Phys. Oceanogr., 6(3), 379389, 1976.

Smith, R. S., Dubois, C., and Marotzke, J.: Global climate and ocean circulation on an aquaplanet ocean-atmosphere general circulation model, J. Climate, 19(18), 4719-4737, doi:10.1175/JCLI3874.1, 2006.

Solomon, S., Qin, D., Manning, M., Chen, Z., Marquis, M., Averyt, K. B., Tignor, M., and Miller, H. L.: Contribution of Working Group I to the Fourth Assessment Report of the Intergovernmental Panel on Climate Change, 2007, Cambridge Univ. Press, Cambridge, UK, 2007.
Stone, P. H.: Constraints on dynamical transports of energy on a spherical planet, Dynam. Atmos. Oceans, 2(2), 123-139, 1978.

Tanré, D., Geleyn, J. F., and Slingo, J.: First results of the introduction of an advanced aerosol-radiation interaction in ECMWF low resolution global model, Deepak Publishing, Hampton, VA, USA, 133-177, 1984.

Trindade, R. I. F. and Macouin, M.: Palaeolatitude of glacial deposits and palaeogeography of Neoproterozoic ice ages, C. R. Geosci., 339(3-4), 200-211, doi:10.1016/j.crte.2007.02.006, 2007.

Valcke, S., Caubel, A., Declat, D., and Terray, L.: OASIS Ocean Atmosphere Sea Ice Soil users's guide, CERFACS Tech. Rep. TR/CMGC/03/69, Toulouse, France, 85 pp., 2003.

Voigt, A.: Snowball Earth - Initiation and Hadley Cell Dynamics, Reports on Earth System Science, No. 83/2010, ISSN 16141199, Max Planck Institute for Meteorology Hamburg, Germany, 129 pp., 2010.

Voigt, A. and Marotzke, J.: The transition from the present-day climate to a modern Snowball Earth, Clim. Dynam., 35, 887-905, doi:10.1007/s00382-009-0633-5, 2010. 